\title{
Accuracy and precision of joint space width measurements in standard and macroradiographs of osteoarthritic knees
}

\author{
J C Buckland-Wright, D G Macfarlane, S A Williams, R J Ward
}

\begin{abstract}
Objectives-To improve the reproducibility and accuracy of joint space width (JSW) measurement as an assessment of cartilage loss in patients with osteoarthritis (OA) of the knee by determining how precision and accuracy of JSW measurement were altered by a computerised method of measurement, correction for radiographic magnification, radiography of the knee in the standing semiflexed view, and high definition macroradiography of the knee in the semiflexed view-taking JSW measurements from standard radiographs of OA knees in the extended view as the standard for comparison.

Methods-Twenty five $O A$ and 10 nonarthritic knees were radiographed in the extended view and minimum JSW was measured manually. Conventional and $\times 5$ macroradiographs were taken in the semiflexed view. All radiographs were taken twice on the same day and repeated two weeks later. Automated computerised measurement of minimum JSW was obtained from digitally stored images of all radiographs.
\end{abstract}

Results-For medial compartment JSW measurements, computerised was more accurate than manual, correction for radiographic magnification improved precision and accuracy, measurements in the semiflexed view were more precise and accurate, and macroradiography increased measurement precision. For the lateral compartment JSW measurements, correction for radiographic magnification improved precision and accuracy, and the semiflexed view improved precision only. Conclusions-Protocols defining radiographic and mensural procedures are essential for quality control of knee radiography in the semiflexed view to permit accurate and reproducible measurement of JSW. Macroradiography provides greater precision of JSW measurement.

(Ann Rheum Dis 1995; 54: 872-880)

Assessment of articular cartilage loss is important in the diagnosis and evaluation of disease progression and treatment of osteoarthritis (OA). ${ }^{1}$ For many years, conventional radiographs of the tibiofemoral joint have been the principal method of evaluation in thera- peutic trials. Recent guidelines, endorsed by the World Health Organisation and the International League Against Rheumatism for testing slow acting drugs in $\mathrm{OA}$, recommend that the principal outcome should be the measurement of articular cartilage loss over several years, determined by radiography. ${ }^{2}$

Evaluation of knee radiography techniques show that there was no standardisation in the procedure. Generally, the knee tends to be radiographed weight bearing with the joint in the fully extended position. ${ }^{3}$ Although occasionally specified, ${ }^{4}$ the radiographic position of the joint is not defined at all in many studies, ${ }^{5-7}$ while others recommend alternative views as providing a more reliable assessment of joint space loss. ${ }^{8-10}$ Criteria for defining alignment of the $x$ ray beam are not specified. ${ }^{11}$ Variability in the alignment of the central ray of the $x$ ray beam relative to the centre of the knee joint (joint space) can lead to the bony margins partially obscuring the joint space, preventing accurate and reproducible serial measurements; ${ }^{11}{ }^{12}$ indeed, some have found ${ }^{4}$ a decrease in medial compartment joint space width (JSW) measurement with an alteration in $x$ ray beam alignment. Further, there is no attempt to correct for the effect of radiographic magnification. ${ }^{11}$ In knee radiography, the distance between the centre of a joint and the radiographic film can be large, and may be increased by factors such as obesity or the restriction of joint movement from pain or osteophytosis. Thus any measurement not corrected by the magnification factor will be inaccurate. ${ }^{12}$

There are also limitations in the mensural procedures. The site at which the joint space is measured varies between investigators. ${ }^{12}$ Reliable manual measurements of JSW are difficult to obtain because of inter and intra observer variation.

Recently, in macroradiographic studies of knee $O A,{ }^{1314}$ we used a standing semiflexed view in which the surface of the tibial plateau was horizontal, so that the joint was positioned close to the normal anatomical standing position and to the region of major contact stresses in the tibiofemoral articulation. ${ }^{15} \mathrm{JSW}$ measurements from macroradiographs were found to reflect accurately the thickness of the articular cartilage in the diseased compartment. ${ }^{16}{ }^{17}$ In addition, the computerised method of JSW measurement from digitally stored high definition macroradiographic images overcame limitations of observer variability and was precise. ${ }^{513}$ 
Because standard radiography is the most widely available and understood imaging technique, we set out to determine the accuracy and precision of minimum JSW measurements in the tibiofemoral compartments of patients with knee $O A$ and in a non-arthritic reference group of similar age and sex. Starting with the most widely used method of standard radiography of the knee in the standing fully extended view, we measured minimum JSW using the manual method recommended by the combined WHO-ILAR conference. ${ }^{2}$ We undertook to determine the change in accuracy and precision obtained using the computerised compared with the manual method of measurement in this view of the knee. Then we assessed to what extent correction for radiographic magnification in the extended view radiographs, and reradiography of the knee using the procedure for precise radioanatomical positioning of the joint in the standing semiflexed position ${ }^{1314}$ altered the accuracy or precision of computerised JSW measurement. Finally, we determined the extent to which high definition (microfocal) macroradiography ${ }^{18}{ }^{19}$ altered the precision of JSW measurements of the knee radiographed in the standing semiflexed view.

\section{Patients and methods}

PATIENTS

After receiving Ethics Committee approval and patients' informed consent, we studied 25 patients (22 women, three men). They had a median age of 59 (range 41-82) years, a median disease duration, based on the pain in the signal (most painful) knee, of 6 (range 2-12) years, and a median weight of 75 (range 55-100) kg. All were selected on the basis of clinical assessment and presence of at least two of the following: osteophytes, subchondral sclerosis, and loss of joint space on radiographs. Their status was graded using the Kellgren and Lawrence criteria. ${ }^{20}$ Exclusion criteria included evidence of other types of arthritis, previous trauma, surgical intervention or treatment with corticosteroids. All were seronegative for rheumatoid factor and had an erythrocyte sedimentation rate within the normal range.

The reference group, consisting of 10 volunteer subjects (eight women and two men), median age 50 (range 42-67) years, and median weight 67 (range 52-80) kg, were recruited from medical and laboratory staff in a manner designed to achieve similarity in age, sex, and weight distribution. Clinical and radiographic examination of all reference subjects were normal.

\section{RADIOGRAPHY}

One knee only in the reference and patient groups, and in the latter the most painful, underwent standard and $\times 5$ high definition macroradiography twice on the same day, within a two hour interval, and this was repeated two weeks later.
Standard radiography of the knee in the standing extended view

In this view ${ }^{3}$ the patient stood with feet together with the knees in full extension. With the aid of the positioning light of the $x$ ray tube, the central ray of the horizontal $x$ ray beam was centred on the inferior border of the patella. To determine radiographic magnification, a $6 \mathrm{~mm}$ diameter metal ball mounted in perspex (to improve the definition of the margin of the ball) was taped to the skin just above the head of the fibula (fig 1A).

\section{Standard radiography of the knee in the standing semiflexed view}

Each knee was flexed until the tibial plateau was horizontal relative to the floor, parallel to the central $x$ ray beam and perpendicular to the $x$ ray film (fig 2 ). The degree of flexion ranged between $179^{\circ}$ and $160^{\circ}$, depending on the angle of inclination of the tibial plateau, which varies between individuals. Patients were provided with hand supports to ensure their stability. The centre of the joint, defined by the joint space, was aligned with the centre of the $x$ ray beam with the aid of the tube's positioning light. The precise position of the knee was obtained visually with the aid of fluoroscopy. With the heel fixed, the foot was internally or externally rotated until the tibial spines appeared centrally placed relative to the femoral notch (fig 1B). The average duration of fluoroscopic examination at the first visit was 15 seconds. As before, the metal ball was taped to the side of the knee to enable calculation of radiographic magnification. Immediately after $x$ ray exposure, the outline of the foot was drawn on a large sheet of paper taped to the floor, to facilitate joint repositioning and to reduce time taken during fluoroscopy at subsequent visits to between 2 and 3 seconds.

\section{Macroradiogaphy of the knee in the standing semiflexed view}

Macroradiographs in this view ${ }^{13} 14$ were taken posteroanteriorly to limit the degree of radiographic magnification of the patella and hence the extent to which it obscured the central region of the tibiofemoral joint (fig 1C).

The procedure followed was exactly the same as described above, with the following differences. A cross optic laser was used to align the central ray of the $x$ ray beam with the centre of the joint (the joint space). Radiographic magnification was determined by placing fine wire meshes on the anterior and posterior surfaces of the knee before radiography.

\section{JSW MEASUREMENT}

Margins

The following margins were used for measuring the inter bone distance (fig 1):

Femur: distal convex margin of the condyle in the medial and lateral compartments.

Tibia, medial compartment: a line extending from near the tibial spine to the medial or outer margin, across the centre of the floor of the 

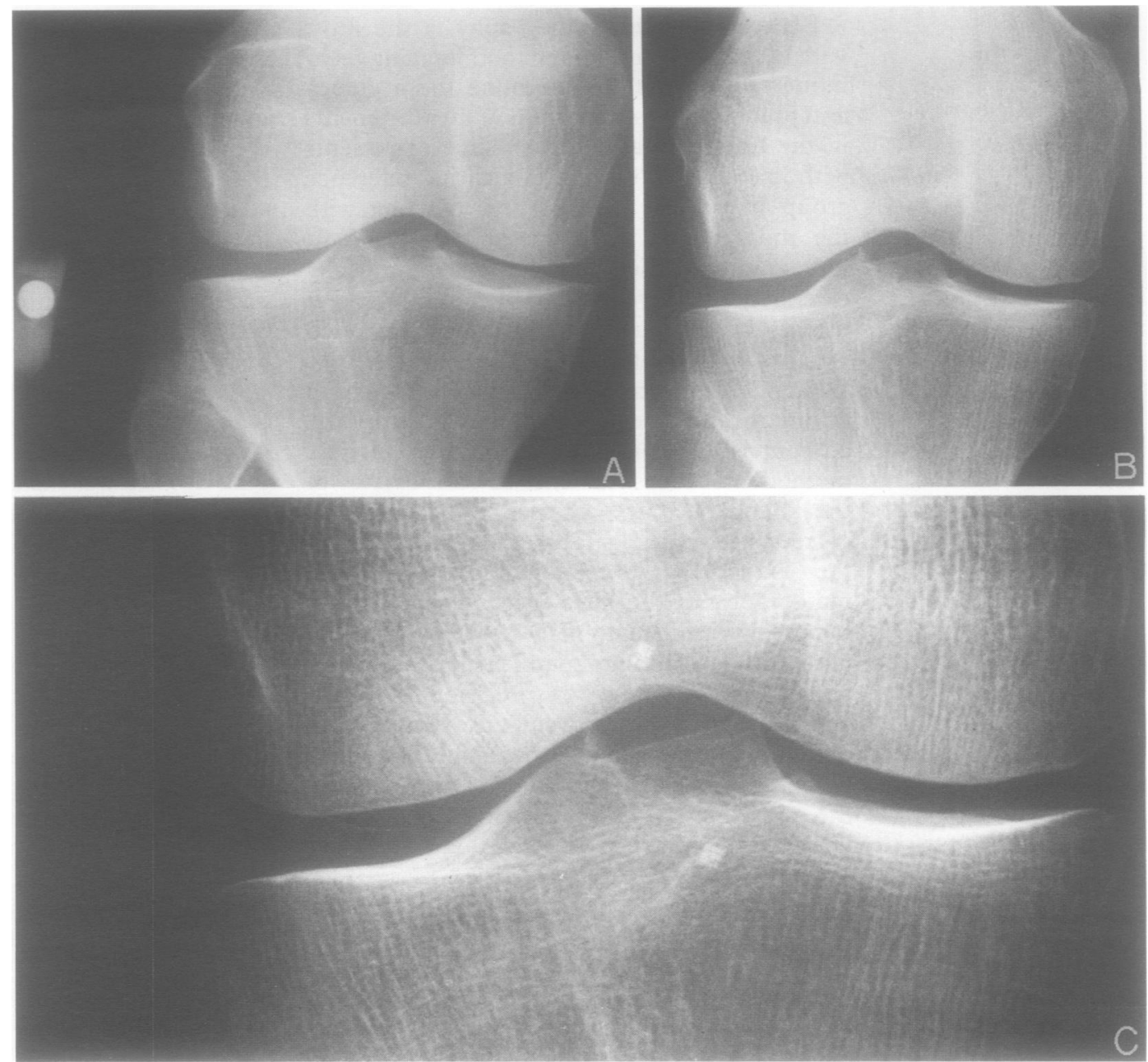

Figure 1 Standard anteroposterior (AP) radiographs of an OA knee. A: Standing fully extended view; B: same knee at same visit, standing semiflexed view. C: Posteroanterior (PA) macroradiograph in the semiflexed view, taken at $\times 5$ magnification. Note that the anatomical configuration of the joint is the same in $B$ and $C$, permitting joint space width measurements to be taken in the same sectional location from radiographs obtained either in AP or PA views. The metal sphere in $A$ and the grids in $B$ were used to determine radiographic magnification.

articular fossa in the mid-coronal plane of the joint. This line was defined by the superior margin of the bright radiodense band of the subchondral cortex, and appeared below the anterior and posterior articular margins of the tibial plateau.

Tibia, lateral compartment: the proximal margin of the articular surface, defined by the superior margin of the bright radiodense band of the subchondral cortex extending from near the tibial spine to the lateral or outer margin.

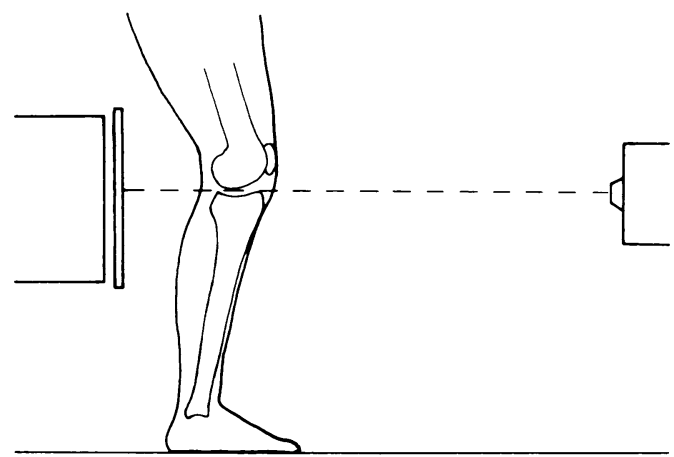

Figure 2 Diagram of the leg in the standing semiflexed position and its position relative to the $\mathrm{x}$ ray tube on the position and its position relative to the $\mathbf{x}$ ray tube on the
right and the film cassette placed in front of the image intensifier tube to the left. In this position the tibial plateau is horizontal, parallel to the central $\mathrm{x}$ ray beam (broken line) and perpendicular to the $\mathrm{x}$ ray film.

\section{Manual measurement}

We followed Lequesne's method, ${ }^{21}$ in which the points of a pair of dividers are used to measure the inter bone distance on the radiograph, at the perceived narrowest point of the joint space. ${ }^{2}$ The dividers are then used to prick a sheet of paper and the distance between the centre of the pin pricks measured using a $\times 10$ magnifying lens fitted with a $10 \mathrm{~mm}$ graticule with $0 \cdot 1 \mathrm{~mm}$ divisions. All assessments were carried out by one observer (RJW) whose coefficient of variation for repeat measures was $3 \cdot 8 \%$.

\section{Digitisation of radiographs}

All standard and macroradiographs were digitised using a CCD camera linked via a Univision UPX1000 frame grabber on a Univision UDC2600 display board in an IBM PC-AT 80486 computer. $^{13}$ The camera digitised the radiographic image at a resolution corresponding to a pixel size of $0.08 \mathrm{~mm}$. In digitising the standard radiograph of the knee in the fully extended position, the radiographic magnification was assumed to be $1 \cdot 0$. The magnification factor obtained from the metal balls was used to correct the measurements obtained from these radiographs. In all other radiographs, the radiographic magnification determined from the metal balls or grids was 
used to set the distance between the digitising camera and film to produce an actual image resolution of $0.08 \mathrm{~mm}$. This ensured that differences between techniques were not influenced by the digitisation process. The digital images of the radiographs were written to a SUN SPARCstation LX (SUN Microsystems Ltd) for image analysis.

\section{Automated measurement}

Specially prepared computer programs written in $C$ were used to measure automatically the minimum JSW within each compartment. ${ }^{1314}$ The minimum JSW in a compartment selected by the computer at the first visit, was the same at all subsequent visits, within an experimental error of $\pm 1 \mathrm{~mm}$. All assessments were carried out by one observer (RJW). The coefficient of variation (CV) for repeat measures was obtained from a randomly selected set of films of nine $O A$ and nine reference knees, each measured seven times on separate occasions. For standard radiography of the knee in the fully extended position, the CVs for the $O A$ and reference knees in the medial compartment were $4.9 \%$ and $1.7 \%$, respectively, and in the lateral compartment $3.4 \%$ and $1.8 \%$, respectively. For standard radiography of the knee in the semiflexed position, CVs were similar in the $\mathrm{OA}$ and reference groups, with a value of $1.0 \%$ for the medial and $1.5 \%$ for the lateral compartment. Similarly, the CV values obtained for measurements in the macroradiographs of the $\mathrm{OA}$ and reference knee groups were $0.89 \%$ for the medial and $1.8 \%$ for the lateral compartment.

\section{Radiographic magnification}

The radiographic magnification at the centre of the joint was calculated to within $1 \%$ by comparing the dimensions of the metal ball attached to the knees in the standard radiographs and the dimensions of the wire grids on the anterior and posterior surfaces of the knee in the macroradiographs with their known actual size. The dimensions of the metal ball were measured using a computer program with a reproducibility of $<1 \%$; those of the grids were obtained using a cross wire cursor and digitising tablet with a reproducibility of $2 \cdot 2 \%$. $^{22}$

DATA ANALYSIS

The mean and standard deviation (SD) of minimum JSW measurements ( $\mathrm{mm}$ ) on four occasions were calculated separately for the medial and lateral compartments, for the reference and OA knee groups. For JSW measurements obtained from the standard radiographs of the knee in the fully extended position, manual measurements were taken in the medial compartment only, as previous studies $^{13} 1417$ had shown that measurements obtained on the lateral side were less accurate and had greater variability. The radiographic magnification factor was applied to the computerised JSW measurements obtained from the standard radiographs of the knees in full extension, resulting in two data sets, one of which had been corrected for the effect of radiographic magnification.

Five data sets were created as shown in the column heading of tables 1 and 3. Comparison between each of the four pairs of successive data sets determined the effect of each of the four procedural modifications upon the precision and accuracy of JSW measurements. Ranked-based methods of analysis were used because requirements of normal distribution for parametric methods could not be met. ${ }^{23}$ For all median values, $95 \%$ confidence intervals (CI) were calculated by selecting the data points with certain ranks depending on the number of samples, as specified by Altman. ${ }^{24}$

Precision defined as the reproducibility of a measurement (how close is the agreement between repeat measurements of the same quantity) that is affected by any systematic errors, and inter and intra observer variability, was assessed from the SD of the measurements obtained on four occasions. Median SDs, their associated CIs, and the CV (the median as a percentage of the mean measured JSW) were calculated.

Accuracy was defined as the agreement between the observed measurement and the true value of the measurement. JSW measurements obtained from the high definition macroradiographs were chosen as a 'standard' to assess the accuracy of measurements, as we had previously demonstrated ${ }^{16} 17$ that JSW measurements using this method measure cartilage thickness in the OA compartment reliably and accurately. Accuracy of the JSW measurements was assessed from the mean error in the four measurements, where the error in an individual measurement was the absolute difference between that measurement and the true JSW-that is, the mean value obtained from macroradiographs. Median mean errors, associated CIs, and the median as a percentage of the true JSW were calculated.

\section{Assessment of change in precision and accuracy of FSW measurements}

To determine the difference in JSW measurement precision between a pair of procedures, the difference between each individual's precision, under each pair of procedures, was calculated. The same process was used to calculate the change in JSW measurement accuracy. Our hypothesis was that precision and accuracy would improve (their values decrease) with the change in procedure from left to right in tables 1 and 3. Thus positive differences (those that accorded with the hypothesis) were deemed to represent an improvement in JSW measurement. The median improvement and associated CIs in the precision and accuracy of JSW measurements were calculated. Wilcoxon's test was used to determine the significance between each pair of procedural data sets. In view of the number of comparisons undertaken, the significance level for all statistical tests was set at $\mathbf{p}=0.01$. 


\section{Results}

Of the signal knees in 25 OA patients, 12 were Kellgren and Lawrence grade I, eight were grade II, three grade III, and two had grade IV. Twenty had medial, two had lateral, and three had bi-compartmental OA.

COMPARISON OF MANUAL AND AUTOMATED METHODS OF JSW MEASUREMENTS

There was no significant difference in precision between the two methods of measurement of JSW (CEAM and CEAA in tables 1 and 2). Compared with the manual method, computerised automated measurement of JSW significantly increased the accuracy of measurements in the group of all OA knees, but not in those of the reference group (CEAM and CEAA in tables 3 and 4).

CORRECTING FOR THE EFFECT OF

RADIOGRAPHIC MAGNIFICATION

Radiographic magnification in the films of knees $x$ rayed in the fully extended position had a mean (SD) value of $117.5(106 \cdot 2) \%$ (range $109 \cdot 3-133 \cdot 7 \%$ ). Correcting for the effect of radiographic magnification significantly increased the precision and accuracy of the com- puterised measurements of JSW in the medial and lateral compartment of all OA knees (CEPA and CEAA in tables 1 to 4 ), and the accuracy only in the medial compartment of the reference group (CEPA and CEAA in tables 3 and 4 ).

COMPARISON OF FULLY EXTENDED AND SEMIFLEXED VIEWS IN KNEE RADIOGRAPHY Compared with that in the standing fully extended position, knee radiography in the standing semiflexed view significantly improved the precision and accuracy of computerised measurements of JSW in the medial compartment of the reference group, and the precision of the lateral compartment of the OA group (CFPA and CEPA in tables 2 and 4).

COMPARISON OF STANDARD AND MICROFOCAL RADIOGRAPHY

Compared with measurements from standard radiography, measurement of JSW from high definition macroradiographs of the knee in the semiflexed position was significantly more precise in the medial compartment of the OA group (MFPA and CFPA in tables 1 and 2).

Table 1 Precision of measurements of minimum $¥ S W$ on four occasions, in the medial and lateral compartments of the study groups

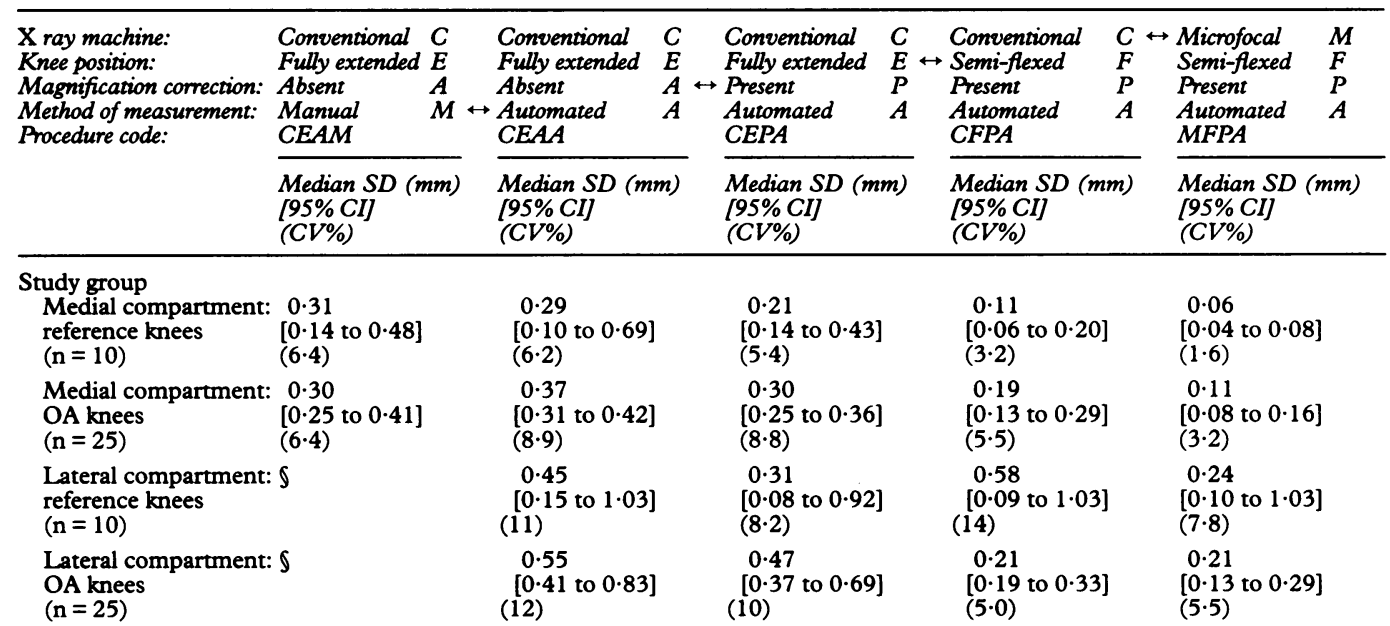

Values are median standard deviation (SD) [associated 95\% confidence interval (CI)], and (coefficient of variation (CV)) for each combination of radiographic and mensural procedures. $\leftrightarrow=$ Methodological difference between adjacent combinations of procedures.

f́Lateral compartment manual measurements not collected (see text).

Table 2 Pairwise comparisons showing the improvements in $7 S W$ measurement precision (based on SD) for the four procedural modifications

\begin{tabular}{|c|c|c|c|c|c|}
\hline \multirow[t]{2}{*}{ Comparison } & \multirow[t]{2}{*}{ Knee group } & \multirow[t]{2}{*}{$n$} & \multicolumn{3}{|l|}{ Improvement in $S D(\mathrm{~mm})$} \\
\hline & & & Medial comparments & \multicolumn{2}{|c|}{ Lateral compartments } \\
\hline $\begin{array}{l}\text { CEAA v CEAM: } \\
\text { Computerised over manual measurement } \\
\text { CEPA v CEAA: } \\
\text { Magnification corrected over uncorrected } \\
\text { CFPA v CEPA: } \\
\text { Semiflexed over fully extended knee } \\
\text { MFPA v CFPA: } \\
\text { Microfocal over standard radiography }\end{array}$ & $\begin{array}{l}\text { OA } \\
\text { Reference } \\
\text { OA } \\
\text { Reference } \\
\text { OA } \\
\text { Reference } \\
\text { OA } \\
\text { Reference }\end{array}$ & $\begin{array}{l}25 \\
10 \\
25 \\
10 \\
25 \\
10 \\
25 \\
10\end{array}$ & $\begin{array}{lr}-0.054 & {[-0.169 \text { to } 0.056]} \\
0.078 & {[-0.116 \text { to } 0.283]} \\
0.067^{\star \star \star} & {[0.002 \text { to } 0.125]} \\
0.046 & {[-0.047 \text { to } 0.304]} \\
0.079^{\star} & {[-0.023 \text { to } 0.143]} \\
0.102^{\star \star \star} & {[0.032 \text { to } 0.354]} \\
0.072^{\star \star \star} & {[0.008 \text { to } 0.173]} \\
0.063^{\star \star} & {[-0.019 \text { to } 0.154]}\end{array}$ & $\begin{array}{l}\int \\
\int \\
0 \cdot 082^{\star \star \star} \\
0 \cdot 081^{\star \star} \\
0 \cdot 212^{\star \star \star} \\
-0.088 \\
0 \cdot 063 \\
0 \cdot 329^{\star \star}\end{array}$ & $\begin{array}{l}\int \\
{[0.010 \text { to } 0.148]} \\
{[0.023 \text { to } 0.193]} \\
{[0.036 \text { to } 0.446]} \\
{[-0.386 \text { to } 0.088]} \\
{[-0.063 \text { to } 0.142]} \\
{[-0.151 \text { to } 0.699]}\end{array}$ \\
\hline
\end{tabular}

Values are median $[95 \%$ confidence interval $]$.

$\star 0.05<\mathrm{p}<0.1 ; \star \star 0.01<\mathrm{p}<0.05 ;{ }^{\star \star} \mathrm{p}<0.01$ (Wilcoxon's matched pairs signed rank sum test) for comparison shown in first column.

§Lateral compartment manual measurements not collected (see text). 
Table 3 Accuracy of measurement of minimum $\mathcal{H S W}$ on four occasions in the medial and lateral compartments of the study groups

\begin{tabular}{|c|c|c|c|c|c|c|c|c|c|}
\hline \multirow[t]{2}{*}{$\begin{array}{l}\text { X ray machine: } \\
\text { Knee position: } \\
\text { Magnification correction: } \\
\text { Method of measurement: } \\
\text { Procedure code: }\end{array}$} & \multicolumn{2}{|c|}{$\begin{array}{lc}\text { Conventional } & C \\
\text { Fully extended } & E \\
\text { Absent } & A \\
\text { Manual } & M \\
C E A M & \end{array}$} & \multicolumn{2}{|c|}{$\begin{array}{ll} & \text { Conventional } \\
\text { Fully extended } & C \\
\text { Absent } & A \\
\leftrightarrow \text { Automated } & A \\
\text { CEAA } & \end{array}$} & \multicolumn{2}{|c|}{$\begin{array}{ll}\text { Conventional } & C \\
\text { Fully extended } & E \\
\leftrightarrow \text { Present } & P \\
\text { Automated } & A \\
\text { CEPA } & \end{array}$} & \multicolumn{2}{|c|}{ 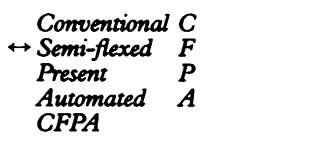 } & \multirow{2}{*}{$\begin{array}{l}\leftrightarrow \text { Microfocal } M \\
\text { Semi-flexed } F \\
\text { Present } P \\
\text { Automated } A \\
\text { MFPA } \\
\text { Mean } \\
\text { min } \\
\text { ISW } \\
(\text { mm })\end{array}$} \\
\hline & 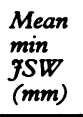 & $\begin{array}{l}\text { Median mean } \\
\text { error }(\mathrm{mm}) \\
{[95 \% \mathrm{CI})} \\
(\mathrm{CV} \%)\end{array}$ & $\begin{array}{l}\text { Mean } \\
\min \\
\mathcal{J S W} \\
(\mathrm{mm})\end{array}$ & $\begin{array}{l}\text { Median mean } \\
\text { error }(\mathrm{mm}) \\
{[95 \% \mathrm{CI}]} \\
(\mathrm{CV} \%)\end{array}$ & $\begin{array}{l}\text { Mean } \\
\text { min } \\
\mathcal{F S W} \\
(\mathrm{mm})\end{array}$ & $\begin{array}{l}\text { Median mean } \\
\text { error }(\mathrm{mm}) \\
{[95 \% \mathrm{CI}} \\
(\mathrm{CV} \%)\end{array}$ & $\begin{array}{l}\text { Mean } \\
\text { min } \\
\mathcal{S S W} \\
(\mathrm{mm})\end{array}$ & $\begin{array}{l}\text { Median mean } \\
\text { error }(\mathrm{mm}) \\
{[95 \% \mathrm{CI}]} \\
(\mathrm{CV} \%)\end{array}$ & \\
\hline $\begin{array}{l}\text { Study group } \\
\text { Medial compartment: } \\
\text { reference knees } \\
(\mathbf{n}=10)\end{array}$ & 4.9 & $\begin{array}{l}1.60 \\
{[0.76 \text { to } 1.80]} \\
(46)\end{array}$ & $4 \cdot 7$ & $\begin{array}{l}1.36 \\
{[0.84 \text { to } 1.53]} \\
(39)\end{array}$ & 3.9 & $\begin{array}{l}0.60 \\
{[0.21 \text { to } 0.76]} \\
(17)\end{array}$ & 3.5 & $\begin{array}{l}0.23 \\
{[0.11 \text { to } 0.58]} \\
(6.6)\end{array}$ & 3.5 \\
\hline $\begin{array}{l}\text { Medial compartment: } \\
\text { OA knees } \\
(\mathrm{n}=25)\end{array}$ & $4 \cdot 7$ & $\begin{array}{l}1.46 \\
{[1.30 \text { to } 1 \cdot 72]}\end{array}$ & $4 \cdot 1$ & $\begin{array}{l}0.90 \\
{[0.60 \text { to } 1.13]} \\
(27)\end{array}$ & 3.4 & $\begin{array}{l}0.47 \\
{[0.31 \text { to } 0.98]} \\
(14)\end{array}$ & 3.5 & $\begin{array}{l}0.29 \\
{[0.23 \text { to } 0.46]} \\
(8 \cdot 8)\end{array}$ & $3 \cdot 3$ \\
\hline $\begin{array}{l}\text { Lateral compartment: } \\
\text { reference knees } \\
(n=10)\end{array}$ & $\delta$ & 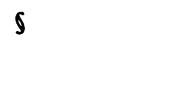 & $4 \cdot 1$ & $\begin{array}{l}0.98 \\
{[0.80 \text { to } 1 \cdot 31]} \\
(32)\end{array}$ & 3.8 & $\begin{array}{l}0.61 \\
{[0.52 \text { to } 0.75]} \\
(20)\end{array}$ & $4 \cdot 1$ & $\begin{array}{l}0.80 \\
{[0.46 \text { to } 0.97]} \\
(26)\end{array}$ & $3 \cdot 1$ \\
\hline $\begin{array}{l}\text { Lateral compartment: } \\
\text { OA knees } \\
(\mathbf{n}=25)\end{array}$ & $\delta$ & 5 & $4 \cdot 7$ & $\begin{array}{l}1 \cdot 42 \\
{[0.30 \text { to } 2 \cdot 04]} \\
(37)\end{array}$ & $4 \cdot 5$ & $\begin{array}{l}0.88 \\
{[0.37 \text { to } 1 \cdot 40]} \\
(23)\end{array}$ & $4 \cdot 3$ & $\begin{array}{l}0.67 \\
{[0 \cdot 31 \text { to } 2 \cdot 44]} \\
(18)\end{array}$ & 3.8 \\
\hline
\end{tabular}

Values are median of the mean absolute errors ( $\mathrm{mm}$ ), [associated $95 \%$ confidence interval], and accuracy as a percentage of the mean JSW obtained from microfocal radiography - used as the standard based upon its previously established accuracy ${ }^{17} . \leftrightarrow=$ Methodological difference between adjacent combinations of procedures. fLateral compartment manual measurements not collected (see text).

Table 4 Pairwise comparisons showing the improvements in ҰSW measurement accuracy (based on mean error) for the four procedural modifications. No comparison could be made between the accuracies of the microfocal and conventional procedures (MFPA v CFPA) because the microfocal procedure provided the standard for assessment of accuracy

\begin{tabular}{|c|c|c|c|c|}
\hline \multirow[t]{2}{*}{ Comparison } & \multirow[t]{2}{*}{ Knee group } & \multirow[t]{2}{*}{$n$} & \multicolumn{2}{|l|}{ Improvement in mean error ( $\mathrm{mm}$ ) } \\
\hline & & & Medial compartments & Lateral compartments \\
\hline $\begin{array}{l}\text { CEAA v CEAM: } \\
\text { Computerised over manual measurement } \\
\text { CEPA v CEAA: } \\
\text { Magnification corrected over uncorrected } \\
\text { CFPA v CEPA: } \\
\text { Semiflexed over fully extended knee }\end{array}$ & $\begin{array}{l}\text { OA } \\
\text { Reference } \\
\text { OA } \\
\text { Reference } \\
\text { OA } \\
\text { Reference }\end{array}$ & $\begin{array}{l}25 \\
10 \\
25 \\
10 \\
25 \\
10\end{array}$ & $\begin{array}{l}0.436^{\star \star \star} \quad[0.330 \text { to } 0.874] \\
0.034 \quad[-0.316 \text { to } 0.880] \\
0.507^{\star \star \star}[0.275 \text { to } 0.631] \\
0.752^{\star \star \star}[0.566 \text { to } 0.931] \\
0.123^{\star} \quad[-0.072 \text { to } 0.380] \\
0.287^{\star \star \star}[-0.071 \text { to } 0.681]\end{array}$ & $\begin{array}{ll}\int & S \\
\int & \int \\
0.478^{\star \star \star} & {[0.229 \text { to } 0.704]} \\
0.590^{\star} & {[-0.131 \text { to } 1.230]} \\
-0.084 & {[-0.429 \text { to } 0.240]} \\
-0.107 & {[-1.251 \text { to } 0.467]}\end{array}$ \\
\hline
\end{tabular}

Values are median $[95 \%$ confidence interval].

${ }^{\star} 0.05<p<0.1 ;{ }^{\star} 0.01<p<0.05 ;{ }^{\star \star \star} p<0.01$ (Wilcoxon's matched pairs signed rank sum test) for comparison shown in first column.

flateral compartment manual measurements not collected (see text).

COMPARISON OF JSW MEASUREMENTS IN THE MEDIAL AND LATERAL COMPARTMENTS

Both precision and accuracy of JSW measurements in the lateral compartment of both groups were poorer, as demonstrated by the wide ranges in the confidence intervals and large coefficients of variation, compared with those obtained from the medial side (tables 1 to 4).

\section{Discussion}

In the medial compartment, computerised rather than manual measurements of minimum JSW in OA knees were significantly more accurate. The errors in the manual method are attributable to the observer's variability in determining the narrowest point in the joint space, whereas the computer program measured the inter bone distance at 300 points across the compartment and selected the narrowest point. ${ }^{13}$ The computer program also ensured that the measurement was perpendicular to the bony margins, a procedure not always easily achieved by an observer.

The absence of a significant difference in precision of JSW measurement between the manual and computerised methods is explained by a lack of standardisation in the radiographic procedure and positional changes, because of different degrees of joint flexion, that result in changes in JSW. ${ }^{11}$ With standard radiographs of the knee in the extended position, others have found no difference between a computerised method over use of a straight rule or semiquantitative assessments. ${ }^{25} 26$ Nevertheless, precise measurements of JSW using a computerised method can be obtained when there is standardisation of the radiographic procedures of the knee $x$ rayed in the semiflexed position. ${ }^{13}$

Correcting for the effect of radiographic magnification significantly increased both the precision and accuracy of the computerised measurements of JSW obtained from the OA knees, but increased the accuracy only in the medial compartment of the reference group of knees (CEPA compared with CEAA in tables 1 to 4 ). The radiographic magnification factor, ranging from $109 \%$ to $134 \%$, was greater than had been expected. It is clear that measurement of any radiographic feature in large joints such as the knee or hip, in which there is a distance between the film and the centre of the joint, does require to be corrected for this effect, by the inclusion of a reference object of known size, such as a metal ball.

Defining the radioanatomical position of the knee determines the plane in which cartilage thickness is to be evaluated, and the bony margins which form the anatomical boundaries of that measurement. Thus in the standing semiflexed view, measurements of JSW were significantly more precise and accurate in the 
medial compartment of the reference group than those obtained from radiographs of the extended position (CFPA and CEPA in tables 1 to 4). Reproducibility in joint repositioning was achieved through the use of fluoroscopy, which ensured that the tibial plateau was horizontal, ${ }^{14}$ and that the degree of joint rotation, known to alter the precision of JSW measurement, was constrained. ${ }^{13}$ Further, the use of a foot map contributed to the reliable repositioning of the joint at successive visits. The lack of a statistically significant improvement in the precision of measurement of JSW in the medial compartment of OA knees radiographed in the semiflexed view compared with the extended view can be attributed to the greater difficulty $\mathrm{OA}$ patients have in reliably repositioning their joints. In contrast to those in the reference group, relocation of the joint in the same plane for OA knee patients was more variable as a result of factors including joint laxity from cartilage loss, differences in the amount of load applied to the joint on successive visits and hence the degree of cartilage compression, ${ }^{17}$ or the amount of joint pain.

The thickness of the articular cartilage at the site of the JSW measurement in the extended and semiflexed knee positions was not measured at identical sectional locations. The difference in cartilage thickness assessed by the two radiographic views was highlighted by the findings in knees of patients with advanced OA (fig 3), in whom a different impression of the amount of cartilage in the joint space was obtained when the knee was in full extension. The apparent increase in JSW on full extension could be caused by the femur riding up on cartilage remaining at the anterior margin of the tibia whereas, in the semiflexed view, the femur would occupy a central position within the articular surface of the tibia, close to the normal standing position and associated contact stresses ${ }^{15}$ - a position in which arthroscopy has revealed greater articular cartilage destruction. ${ }^{9}$ Thus the greater JSW found in knees with advanced OA radio- graphed in the extended position, implies that this measurement is likely to be unreliable not only for the clinical assessment of disease status, but also as a measure of outcome, and as a basis for a patient's inclusion in therapeutic trials. Thus it is conceivable that the limitations of knee radiography in the extended view could account for the failure of investigators to detect significant alterations in the radiological features from longitudinal studies of OA knee, ${ }^{27}{ }^{28}$ leading them to suggest that the anatomical changes in many OA knee joints remain relatively stable for long periods of time. ${ }^{27-30}$

Compared with standard radiography, high definition macroradiography combined with procedures for reproducible joint positioning resulted in a significantly greater precision in measurements of JSW in the OA knee group. The coefficient of variation for JSW measurements in macroradiographs was half that obtained for standard radiography of the knee in the same view (table 1). The increased precision was attributable to the advantages of a micron sized $x$ ray source, ${ }^{18}{ }^{19}$ including those of magnification, high spatial resolution, minimal penumbral blurring, and greater image contrast from reduced $x$ ray scatter as a result of the air gap effect. ${ }^{19}$ These factors enhanced the definition of the radiographic appearance of the articular margins used to measure JSW. In addition, any errors in measurement were reduced by the magnification factor when this was applied to correct the JSW data. ${ }^{13} 31$

In the reference group, precision of microfocal measurement of JSW in the medial compartment was improved by $50 \%$ of that obtained in the OA knees (MFPA in table 1). Here again, the larger variation in JSW measurement within the OA group may have resulted from variations in focal cartilage loss in the two articular surfaces, or from small alterations in the position of the femur on the tibia associated with cartilage loss and the resulting laxity in the ligaments of the joint.
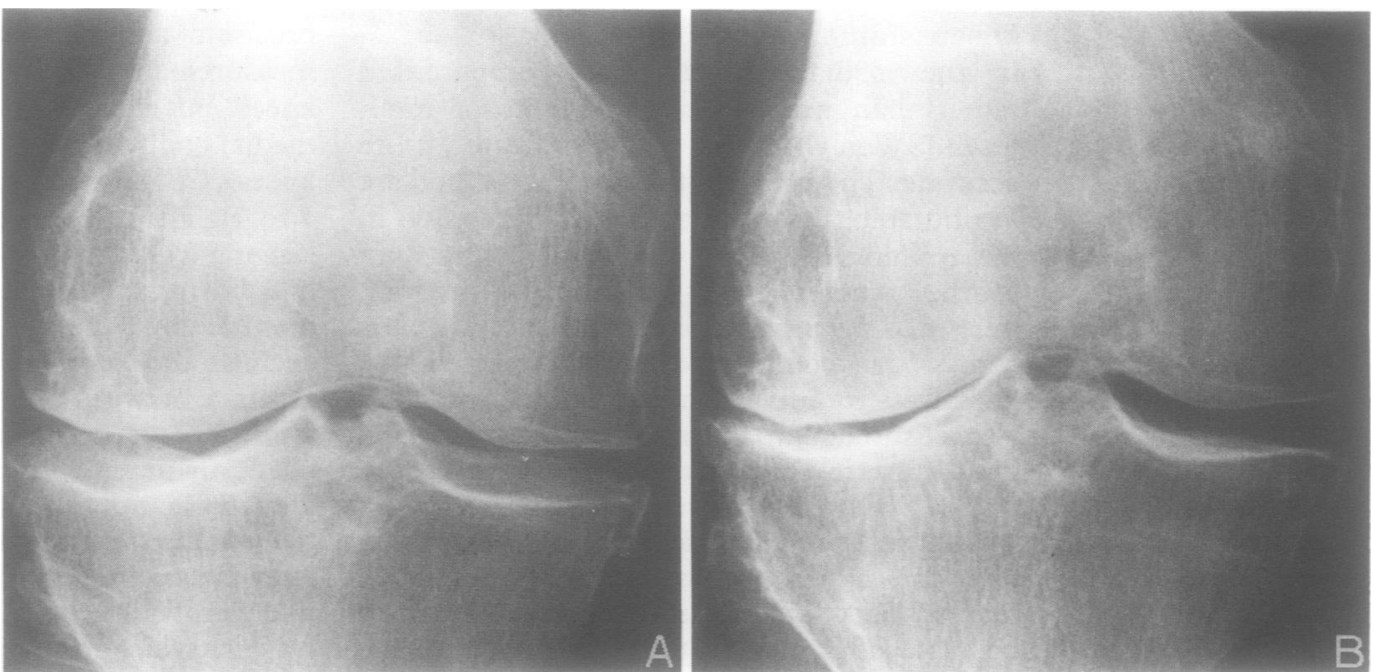

Figure 3 Standard radiograph of an $O A$ knee in the fully extended $(A)$ and the standing semiflexed $(B)$ views. In full extension the femoral condyle rises up on the cartilage remaining at the anterior margin of the tibial plateau, resulting in an increased inter bone distance compared with that seen in the semiflexed view. 
Examination of data from individual patients revealed that precision of JSW measurement decreased in knees with advanced OA (Kellgren and Lawrence grade IV)-that is, those compartments with marked joint space narrowing, attrition and an altered configuration in the appearance of the bony articular surfaces. By omitting the data for these knees, the precision of measurement of JSW was increased in the remaining OA knee group. The median standard deviation for JSW measurements from macroradiographs was reduced from $0.11 \mathrm{~mm}$ (table 1) to $0.10 \mathrm{~mm}$ giving a CV of $2.9 \%$. Thus JSW measurements in knees with early disease were more precise than those with more advanced disease, which is of particular importance because changes in JSW in knees with early disease are more likely to show the effect of a therapeutic agent. ${ }^{43}$

As a further illustration of the practical significance of the findings in this study, we followed Cummings and Black's method ${ }^{33}$ to calculate the minimum interval change in medial compartment JSW that could be measured with $95 \%$ confidence from the semiflexed knee radiographs. Using the data in table 1 , for standard radiography these intervals amounted to between $9 \%$ and $15 \%$ of the minimum joint space in knees ranging in disease severity from those with early (Kellgren and Lawrence grade 0) to advanced disease (Kellgren and Lawrence grade III). For macroradiography of the knee in the same position, the equivalent figures are between $4 \%$ and $9 \%$ of the minimum joint space for diseased knees having Kellgren and Lawrence grades ranging from 0 to III. Both these figures, for standard and macroradiography are within the range of clinical usefulness for monitoring cartilage loss over time in the tibiofemoral compartments of patients with arthritis. The values for standard radiography are comparable to those quoted for quantifying articular cartilage volume changes in arthritic knees using pulsed saturation transfer subtraction (STS) and fat suppressed (FS) magnetic resonance (MR) imaging. ${ }^{34}$ The value either of the standard radiographic method described here or of STS and FS MR imaging in quantifying disease related changes in articular cartilage has yet to be determined.

In the lateral compartment, the poorer precision and accuracy of all measurements in OA knees compared with those on the medial side was consistent with observations from other studies ${ }^{13141725}$ and is attributable to the variable degree of subluxation in this compartment as a result of medial compartment disease. ${ }^{13} 35$ Similar findings for precision and accuracy in the lateral compartment of the non-arthritic knees suggest that the articular surfaces in the normal load bearing medial compartment $^{15}$ are more closely applied than those on the lateral side. Nevertheless, our findings show that correcting for the effect of radiographic magnification significantly improved precision and accuracy of JSW measurements, and these were more precise in the semiflexed view. Whether the precision and accuracy of JSW meaurements in the knees of patients with lateral compartment disease would be comparable to that reported here for the medial compartment is not known and requires investigation.

For many of the paired comparison tests conducted in this study (tables 2,4 ), significant differences in the effects being evaluated were found between the $\mathrm{OA}$ and reference groups. While the differences detected could be caused by real differences between the groups, they may also reflect the small number of knees studied in the reference group. Studies involving larger numbers of knees would be necessary to validate the differences. Investigations are currently in progress to validate a method for positioning the knee in the standing semiflexed view without the aid of fluoroscopy, to determine the precision of manual methods of measurement of JSW in this view and the effects, if any, of any variability in repositioning the metal ball on the patient, above the head of the fibula.

In conclusion, errors of precision in the measurement of JSW of OA knees radiographed without standardised procedures and in the fully extended position are great and are attributable to the inherent radiographic magnification and difficulties in reselecting identical sectional locations and orientation at follow up visits. However, realignment based upon procedures giving a precise radioanatomical position of the joint, which rely upon unchanging landmarks, plus correction for radiographic magnification, do offer a solution, as shown by the significantly increased precision and accuracy of JSW measurements we obtained with the knee in the standing semiflexed position. Precision of these measurements was further increased significantly with the use of high definition macroradiography. The advantage of this method in imaging features accurately, ${ }^{17}$ and the precision of the computerised method of JSW measurement in OA knee macroradiographs ${ }^{13}{ }^{31}$ permit disease related changes in joint anatomy to be quantified within as short a period as 12 or 18 months, ${ }^{36-38}$ detection of different patterns of articular cartilage loss in OA knees, ${ }^{14}$ and quantification of the effect of therapeutic intervention upon joint space narrowing within an 18 month period. ${ }^{33}$

The study was supported by a grant from Pfizer Central Research, Pfizer Inc, USA. The authors wish to thank Judy Vlahovic and the radiographers of the Nuffield X-ray Unit for their superb technical assistance, and Kevin Fitzpatrick and Sarah Smith for preparing the photographs.

1 Jonsson K, Buckwalter K, Helvie M, Niklason L, Martel W. Precision of hyaline cartilage thickness measurements. Acta Radiol 1992; 33: 234-9.

2 Lequesne M, Brandt K, Bellamy R, et al. Guidelines for testing slow acting drugs in OA. Proc. Vth joint WHO and IILAR meeting. $\mathcal{F}$ Rheumatol 1994; 21 (suppl 41): 65-73. ILAR meeting. $\mathcal{F}$ Rheumatol 1994; 21 (suppl 41): 65-73.
3 Ahlback S. Osteoarthritis of the knee: a radiographic investigation. Acta Radiol 1968; 277 (suppl): 7-72.

4 Fife R S, Brant K D, Braunstein E M, et al. Relationship between arthroscopic evidence of cartilage damage and radiographic evidence of joint space narrowing in early osteoarthritis of the knee. Arthritis Rheum 1991; 34: 377-82

5 Dacre J E, Coppock J S, Herbert K E, Perrett D, Huskisson E C. Development of a new radiographic scoring system using digital image analysis. Ann Rheum Dis 1989; 48: 194-200.

6 Schouten J S A G, van den Ouweland F A, Valkenburg H A. A 12 year follow up study in the general population on prognostic factors of cartilage loss in osteoarthritis of the knee. Ann Rheum Dis 1992; 51: 932-7. 
7 Dougados M, Gueguen A, Nguyen M, et al. Longitudinal radiologic evaluation of osteoarthritis of the knee. f Rheumatol 1992; 19: 378-84.

8 Resnick D, Vint V. The "tunnel" view in assessment of cartilage loss in osteoarthritis of the knee. Radiology 1980; 137: 547-8.

9 Messieh S S, Fowler P J, Munro T. Anteroposterior radiographs of the osteoarthritic knee. F Bone foint Surg Br 1990; 72: 639-40.

10 Rosenberg T D, Paulos L E, Parker E D, et al. The fortyfive-degree posteroanterior flexion weight-bearing radiograph of the knee. $f$ Bone foint Surg Am 1988; 70: 1479-83.

11 Buckland-Wright J C. Quantitative radiography of osteoarthritis. Ann Rheum Dis 1994; 53: 268-75.

12 Buckland-Wright J C, Macfarlane D G. Radioanatomic assessment of therapeutic outcome in osteoarthritis. In: assessment $\mathrm{C}$ the Rosemont: American Academy of Orthopedic Surgeons, 1995; 51-65.

13 Lynch J A, Buckland-Wright J C, Macfarlane D G. Precision of joint space width measurement in knee osteoarthritis from digital image analysis of high definition macroradiographs. Osteoarthritis Cartilage 1993; 1: 209-18.

14 Buckland-Wright J C, Macfarlane D G, Jasani M K, Lynch J A. Quantitative microfocal radiographic assessment of osteoarthritis of the knee from weight bearing tunnel and semi-flexed standing views. F Rheumatol 1994; 21: $1734-41$.

15 Maquet P. Biomechanics of the knee. Berlin: Springer-Verlag, 1976.

16 Buckland-Wright J C, Macfarlane D G, Jasani M K, Lynch J A. Joint space width measures cartilage thickness in knee OA: plain film and double contrast macroradioin knee OA: plain film and double contrast macroradio-

17 Buckland-Wright J C, Macfarlane D G, Lynch J A, Jasani M K, Bradshaw C R. Joint space width measures cartilage thickness in osteoarthritis of the knee: high resolution plain film and double contrast macroradiographic investigation. Ann Rheum Dis 1995; 54: 263-8.

18 Buckland-Wright J C. A new high definition microfocal X-ray unit. Br f Radiol 1989; 62: 201-8.

19 Buckland-Wright J C, Bradshaw C R. Clinical applications of high definition microfocal radiography. $\mathrm{Br} \mathcal{F}$ Radiol 1989; 62: 209-17.

20 Kelloren J H, Lawrence J S. Radiological assessment of osteoarthrosis. Ann Rheum Dis 1957; 16: 494-501.

21 Lequesne $M$. Quantitative measurements of joint space during progression of osteoarthritis: chondrometry. In: Kuettmer K E, Goldberg V, eds. Osteoarthritic disorders. Rosemont: American Academy of Orthopedic Surgeons, $1995 ; 427-44$

22 Buckland-Wright J C, Clarke G S, Chikanza I C, Grahame R. Quantitative microfocal radiography detects changes in erosion area in patients with early rheumatoid arthritis treated with myocrisine. F Rheumatol 1993; 20: 243-7.

23 Dudewicz E J, Mishra S N. Modern mathematical statistics. New York: Wiley, 1988; 658.
24 Altman D G. Table B11. In: Practical statistics for medical research. London: Chapman and Hall, 1991; 60-3.

25 Spector T D, Hart D J, Byrne J, et al. Definition of osteoarthritis of the knee for epidemiological studies. Ann Rheum Dis 1993; 52: 790-4.

26 Spector T D, Hart D J, Doyle D V. Incidence and progression of osteoarthritis in women with unilateral progression of osteoarthritis in women with unilateral obesity. Ann Rheum Dis 1994; 55: 565-8.

27 Massardo L, Watt I, Cushnaghan J, Dieppe P. Osteoarthritis of the knee joint: an eight year prospective study. Ann Rheum Dis 1989; 48: 893-7.

28 Spector T D, Dacre J E, Harris P A, Huskisson E C. Radiological progression of osteoarthritis: an 11 year follow up study of the knee. Ann Rheum Dis 1992; 51: $1107-10$.

29 Dieppe P, Cushnaghan J. The natural course and prognosis of osteoarthritis. In: Moskowitz R W, Howell D S, Goldberg V M, Mankin H J, eds. Osteoarthritis: diagnosis and medical and surgical management, 2nd edn. and medical and surgical management,

30 Dieppe P, Cushnaghan J, Jasani M K, McCrae F, Watt I. A two year, placebo-controlled trial of non-steroidal antiinflammatory therapy in osteoarthritis of the knee joint. Brf Rheumatol 1993; 32: 595-600.

31 Buckland-Wright J C, Carmichael I, Walker S R Quantitative microfocal radiography accurately detects joint changes in rheumatoid arthritis. Ann Rheum Dis 1986; 45: 463-7.

32 Buckland-Wright J C, Macfarlane D G, Lynch J A, Jasani M K. Quantitative microfocal radiography detects changes in OA knee joint space width in patients in changes in OA knee joint space width in patients in 1995; 22: 937-43.

33 Cummings S R, Black D. Should perimenopausal women be screened for osteoporosis? Ann Intern Med 1986; 104: 817-23.

34 Peterfy C G, Dijke C F van, Janzen D L, et al. Quantification of articular cartilage in the knee with pulsed saturation transfer subtraction and fat-suppressed MR imaging: optimization and validation. Radiology 1994; 192: 485-91.

35 Thomas R H, Resnick D, Alazraki N P, Daniel D, Greenfield R. Compartmental evaluation of osteoarthritis of the knee. A comparative study of available diagnostic modalities. Radiology 1975; 116: 585-94.

36 Buckland-Wright J C, Macfarlane D G, Lynch J A, Clark B. Quantitative microfocal radiographic assessment of progression in osteo

37 Buckland-Wright J C, Macfarlane D G, Lynch J A. Osteophytes in the arthritic hand: their incidence, size, distribution and progression. Ann Rheum Dis 1991; 50: 627-30.

38 Buckland-Wright C, Macfarlane D, Lynch J. Relationship between joint space width and subchondral sclerosis in the osteoarthritic hand: a quantitative microfocal study. f Rheumatol 1992; 19: 788-95. 